Meta-analysis

\title{
Comparing Pain Reduction Following Kyphoplasty and Vertebroplasty for Osteoporotic Vertebral Compression Fractures
}

J. Brian Gill, MD, Mark Kuper, DO, Paul C. Chin. PhD, Yan Zhang, PhD, and Robert Schutt, Jr., MD

From: Texas Tech University Health Sciences Center, Lubbock, Texas.

Dr. Gill is with the Dept of Orthopaedic Surgery and Rehabilitation Texas Tech University Health Sciences Center, Lubbock, TX.

Dr. Kuper is with Dept. of Orthopaedic Surgery and Rehabilitation, Texas Tech

University Health Sciences Center, Lubbock, T.X

Dr. Chin is with Texas Tech University Health Sciences Center, Lubbock,

TX. Dr Zhang is Assistant Professor, Division of Health Services Research, Dept of Family \& Community Medicine, Texas Tech University Health Sciences Center, Lubbock, TX.

Dr. Schutt is Associate Professor and Chairman, Dept of Orthopaedic Surgery and Rehabilitation, Texas Tech University Health Sciences Center, Lubbock, TX

Address correspondence: Brian Gill, MD

Dept of Orthopaedic Surgery and Rehabilitation Texas Tech University Health Sciences Center 36014 th Street/ MS 9436 Lubbock, TX 79430

E-mail: brian.gill@ttuhsc.edu

Disclaimer: No external funding was received for this study.

Conflict of interest: None Manuscript received: 03/12/2007 Revisions accepted: 05/15/2007 Accepted for Publication: 05/29/2007

Free full manuscript: www.painphysicianjournal.com
Background: Osteoporosis with subsequent osteoporotic vertebral compression fractures is an increasingly important disease due not only to its significant economic impact but also to the increasing age of our population. Pain reduction and stabilization are of primary importance with osteoporotic vertebral compression fractures. Although many patients heal with conservative treatment consisting of rest or activity modification, analgesics, and bracing, the management of severe pain compels some patients to seek surgical intervention via 2 procedures: vertebroplasty and kyphoplasty. Although there is abundant support in the literature for both procedures, there remains debate over which procedure can most successfully reduce patients' perception of pain.

Objective: To determine the amount of pain reduction using the visual analog scale (VAS) with kyphoplasty and vertebroplasty in the treatment of osteoporotic vertebral compression fractures.

\section{Design: Meta-analysis}

Methods: A systematic review and meta-analysis of the available literature was performed to quantify the amount of pain reduction using the visual analog scale (VAS) between vertebroplasty and kyphoplasty for osteoporotic vertebral compression fractures.

Results: Twenty-one studies, 14 vertebroplasty and 7 kyphoplasty, qualified for inclusion representing totals of 1,046 vertebroplasty and 263 kyphoplasty patients treated, respectively. Kyphoplasty and vertebroplasty resulted in a more than 5 point drop in the VAS in the immediate postoperative period $(p<0.00001)$. Between the two, the difference in early pain relief was not significant. At final follow-up, the long-term VAS was improved for both procedures, but the final follow-up VAS for vertebroplasty and kyphoplasty was not significant when compared to the initial postoperative VAS $(p=0.25, p=0.38$, respectively).

Conclusions: The analysis demonstrates that both procedures reduce the amount of pain in the immediate postoperative period by approximately $50 \%$. Both procedures reduce pain in symptomatic osteoporotic vertebral compression fractures that have failed conservative treatment. Randomized controlled trials are needed to provide definitive data on which procedure is the most effective for vertebral compression fractures.

Key words: vertebroplasty, kyphoplasty, vertebral compression fracture, osteoporosis

Pain Physician 2007; 10:583-590 
$\mathrm{T}$ he World Health Organization (WHO) has recently identified the need for a global strategy for prevention and control of osteoporosis (1). Once viewed as an inescapable consequence of aging, osteoporosis is an increasingly important disease due not only to its significant economic impact but also to the increasing age of our population. Estimates in 1995 attributed health care expenditures related to osteoporotic fractures at $\$ 13.8$ billion (2). This expenditure and the 700,000 estimated number of vertebral fractures each year in the U.S. will likely increase in accordance with our elderly population, which by the year 2030 will exceed $20 \%$ of the U.S. population $(3,4)$. Thus, osteoporotic vertebral compression fractures constitute an important public health concern.

Pain reduction and stabilization is of primary importance with osteoporotic vertebral compression fractures. Many patients heal with conservative treatment consisting of rest or activity modification, analgesics, and bracing. For those patients with severe recalcitrant pain, vertebroplasty and kyphoplasty are alternative treatment options for the management of severe pain. Initially reported by Galibert et al in 1987, vertebroplasty involved the destruction of an angioma through consolidation of the vertebral column by percutaneous injection of acrylic cementר (5); however, vertebroplasty is now commonly used in treatment of painful osteoporotic vertebral compression fractures (6). Kyphoplasty involves the use of an inflatable bone tamp that when introduced into the vertebral body, restores vertebral height and forms a space for injection of acrylic cement (7).

There is debate over which procedure can most successfully reduce patients' perception of pain. In this study, we conduct a systematic review and metaanalysis of the available literature in order to quantify the amount of pain reduction between vertebroplasty and kyphoplasty for osteoporotic vertebral compression fractures.

\section{Methods}

Prospective and retrospective clinical trials that met certain inclusion criteria were analyzed in this meta-analysis. The inclusion criteria were: a) all peerreviewed English literature up to April 2007, b) diagnosis of osteoporotic vertebral compression fractures as the major study population (studies exclusively examining osteolytic tumors were excluded), c) treatment included vertebroplasty or kyphoplasty only, and d) use of the visual analog scale (VAS) as an objective measure of pain. Although the far majority of studies reported using a VAS, the studies actually used a numerical rating scale (ordinal scale $0-10$ ). A few studies did use an actual VAS (continuous scale $0-100$ ). The studies that used the continuous scale were excluded from the analysis due to the fact that fewer studies used this scale. Although these two scales provide similar information in regards to pain perception, one cannot be substituted for the other (8). We initially also included articles measuring functional outcomes in patients after either procedure, but the reported data on functional outcomes was limited and varied. Therefore, we were unable to do an accurate and reliable meta-analysis for functional outcome data.

We performed computerized searches, in duplicate, of online databases PubMed MEDLINE and OVID MEDLINE with the following terms: "vertebroplasty," "kyphoplasty," and "compression fracture," as well as, searched the Cochrane Center Register of Controlled Trials. Additionally, a manual search of English scientific literature was performed by cross-checking the bibliographies of selected articles. From the selected articles, data extraction included: a) VAS obtained preoperatively, initial postoperatively, and final follow-up (minimum 6 months), b) type of compression fracture, c) mean age, and d) gender.

All identified studies were reviewed by all of the authors. Using the pre-established inclusion criteria, each article was evaluated for inclusion or exclusion from the meta-analysis. Any disagreements between the authors were resolved by discussion to reach a consensus. If the articles did not report mean VAS and/or the standard deviation, then the authors were contacted to try and obtain the correct data. The outcome measures were recorded in a spreadsheet and checked by the authors to ensure that they were accurate and correct. These measures were then entered into The Cochrane Collaboration's Review Manager (RevMan version 4.2) and cross-checked. Only studies with reported mean and standard deviation were included in the statistical analysis. Preoperative, initial postoperative, and final follow-up VAS were reported as weighted mean difference using the random effect model. The mean difference in VAS between specific groups was used to calculate weighted mean difference (WMD). A test for heterogeneity was performed using the Chisquare and a test for overall effect was performed using a student's t test. 


\section{Results}

The analysis yielded a total of 21 articles eligible for analysis (9-29). The 20 studies, 14 vertebroplasty and 7 kyphoplasty, that qualified for inclusion rep-

Table 1. Accepted Studies for Meta-analysis

\begin{tabular}{|c|c|c|c|c|c|c|c|c|c|c|}
\hline $\begin{array}{l}\text { Kyphoplasty } \\
\text { Group }\end{array}$ & $\begin{array}{c}\# \\
\text { of } \\
\text { Pts }\end{array}$ & Study & $\begin{array}{l}\text { Preop } \\
\text { VAS }\end{array}$ & $\begin{array}{c}\text { Postop } \\
\text { VAS (2 } \\
\text { days; 1-30 } \\
\text { days) }\end{array}$ & $\begin{array}{l}\text { Final Follow- } \\
\text { up VAS (1.25 } \\
\text { yrs; 1-2 yrs) }\end{array}$ & $\begin{array}{c}\text { Mean } \\
\text { Age }\end{array}$ & Female & Male & Osteoporosis & $\begin{array}{c}\text { Tumor/ } \\
\text { Metastasis }\end{array}$ \\
\hline Berlemann et $\mathrm{al}^{10}$ & 27 & Pro & $8.4(1.63)$ & $3.8(0.80)$ & $1.5(0.45)$ & 65.5 & 12 & 12 & 27 & 0 \\
\hline Crandall et al ${ }^{11}$ & 47 & Pro & $7.3(2.1)$ & $4.3(2.7)$ & & 74 & 35 & 12 & 47 & 0 \\
\hline Deen et al ${ }^{12}$ & 10 & Pro & $9.3(0.82)$ & $3.2(2.3)$ & $2.9(2.64)$ & 62.600 & 3 & 7 & 10 & 0 \\
\hline Deen II et al ${ }^{12}$ & 10 & Pro & $7.7(1.64)$ & $1.5(1.51)$ & $2.0(1.73)$ & 74 & 9 & 1 & 10 & 0 \\
\hline Ledlie et a ${ }^{19}$ & 77 & Retro & $8.9(1.5)$ & $2.8(2.9)$ & $1.5(1.8)$ & 76.200 & 53 & 24 & 76 & 1 \\
\hline Machinis et $\mathrm{al}^{21}$ & 24 & Retro & $7.8(1.0)$ & $1.4(0.9)$ & $2.2(0.8)$ & 72.600 & 16 & 8 & 24 & 0 \\
\hline Voggenreiter et $\mathrm{al}^{27}$ & 30 & Pro & $8.7(1.4)$ & $2.3(0.9)$ & & 70.100 & 23 & 7 & 30 & 0 \\
\hline Zhang et $\mathrm{a}^{29}$ & 38 & Retro & $8.2(1.6)$ & $2.4(0.84)$ & $1.7(0.76)$ & 72 & 28 & 10 & 38 & 0 \\
\hline Total & 263 & & & & & & & & 262 & 1 \\
\hline $\begin{array}{l}\text { Vertebroplasty } \\
\text { Group }\end{array}$ & $\begin{array}{c}\# \\
\text { of } \\
\text { Pts }\end{array}$ & Study & $\begin{array}{c}\text { Preop } \\
\text { VAS }\end{array}$ & $\begin{array}{c}\text { Postop } \\
\text { VAS ( } 7 \\
\text { days; 1day } \\
\text { - } 30 \text { days) }\end{array}$ & $\begin{array}{c}\text { Final Follow- } \\
\text { up VAS (2 } \\
\text { yrs; } 6 \text { months } \\
\text { - 5yrs) }\end{array}$ & $\begin{array}{c}\text { Mean } \\
\text { Age }\end{array}$ & Female & Male & Osteoporosis & $\begin{array}{c}\text { Tumor/ } \\
\text { Metastasis }\end{array}$ \\
\hline Appel and Gilula ${ }^{9}$ & 23 & Retro & $7.6(2.0)$ & $1.7(1.8)$ & & 72 & 17 & 6 & 16 & 7 \\
\hline Do et $\mathrm{al}^{13}$ & 167 & Pro & $8.71(1.29)$ & $2.77(2.33)$ & & 74.600 & 127 & 40 & 167 & 0 \\
\hline Evans et $\mathrm{a}^{14}$ & 245 & Retro & $8.9(1.7)$ & $3.4(2.7)$ & & 76 & 184 & 61 & 245 & 0 \\
\hline Heini et $\mathrm{al}^{15}$ & 17 & Pro & $7.5(1.86)$ & $3.2(0.97)$ & $3.4(0.89)$ & 74 & 15 & 2 & 17 & 0 \\
\hline Kalmes et a ${ }^{16}$ & 31 & Retro & $9.7(1.0)$ & $1.7(1.9)$ & & & 0 & 0 & 31 & 0 \\
\hline Kobayashi et al ${ }^{17}$ & 196 & Pro & $7.22(1.89)$ & $2.07(1.89)$ & & 77.900 & 0 & 0 & 196 & 0 \\
\hline Komemushi et a ${ }^{18}$ & 49 & Pro & $7.4(2.2)$ & $2.5(2.7)$ & & 72.5 & 36 & 10 & 48 & 1 \\
\hline Liliang et $\mathrm{a}^{20}$ & 16 & Pro & $8.9(0.6)$ & $4.3(3.1)$ & $2.8(2.2)$ & 76.600 & 12 & 4 & 16 & 0 \\
\hline McGraw et a ${ }^{22}$ & 99 & Pro & $8.91(1.12)$ & $2.02(1.95)$ & & 73.700 & 79 & 20 & 94 & 5 \\
\hline McKiernan et $\mathrm{a}^{23}$ & 46 & Pro & $7.7(1.8)$ & $2.8(1.8)$ & & 74.300 & 32 & 14 & 46 & 0 \\
\hline Perez-Higueras et al ${ }^{24}$ & 13 & Pro & $9.07(0.6)$ & $2.07(1.14)$ & $2.15(2.6)$ & 67 & 10 & 3 & 13 & 0 \\
\hline Prather et $\mathrm{al}^{25}$ & 50 & & $7.76(2.18)$ & $3.10(2.90)$ & $2.90(7.00)$ & 68.600 & 31 & 19 & 50 & 0 \\
\hline Tanigawa et $\mathrm{al}^{26}$ & 76 & Pro & $7.2(2.0)$ & $2.5(2.3)$ & $1.0(0.2)$ & & & & & \\
\hline Voormolem et $\mathrm{al}^{28}$ & 18 & Pro & $7.1(1.3)$ & $4.7(2.1)$ & & 72 & 14 & 4 & 18 & 0 \\
\hline Total & 1046 & & & & & & & & 957 & 13 \\
\hline
\end{tabular}

$\#=$ number $;$ VAS = visual analog scale; ()$=$ standard deviation $;$ Retro $=$ retrospective $;$ Pro $=$ prospective

www.painphysicianjournal.com resented a total of 1,046 vertebroplasty and $263 \mathrm{ky}-$ phoplasty patients treated, respectively. A list of the accepted studies for the meta-analysis is provided in Table 1. 


\section{Demographics}

The analysis of the demographic data revealed that the average age of a patient that undergoes kyphoplasty or vertebroplasty is 72.3 years. Overall, females are 3 times more likely than males to undergo these procedures as well. More detailed demographic data can be found in Table 2. When the kyphoplasty studies are compared to the vertebroplasty studies no statistically significant difference is found between the groups in regards to age, gender, or the etiology of the vertebral compression fractures (osteoporosis or tumor/metastasis).

\section{Analysis Results}

Three comparisons were conducted: the change in preoperative VAS to initial postoperative VAS, preoperative VAS to final follow-up VAS, and initial postoperative VAS to final follow-up VAS. Table 3 shows the detailed analysis results and the confidence intervals for both kyphoplasty and vertebroplasty WMD. Figure 1 is a graphical representation of the average VAS and standard deviations provided by the included studies for the preoperative, immediate postoperative and final follow-up periods, respectively.

Table 2. Demographic Data

\begin{tabular}{|l|c|c|c|c|c||}
\hline & Age & \# of Females & \# of Males & $\begin{array}{c}\text { \# of Osteoporosis } \\
\text { Fractures }\end{array}$ & $\begin{array}{c}\text { \# of Tumor/Metastasis } \\
\text { Fractures }\end{array}$ \\
\hline Kyphoplasty & $70.9(4.63)$ & $22.4(16.18)$ & $10.1(6.62)$ & $32.8(21.56)$ & $0.1(0.35)$ \\
\hline Vertebroplasty & $73.3(3.14)$ & $50.6(56.79)$ & $16.6(18.48)$ & $73.6(78.47)$ & $1.0(2.27$ \\
\hline P-value & 0.23 & 0.23 & 0.48 & 0.1 & 0.2 \\
\hline
\end{tabular}

Values are expressed as mean (standard deviation); \# = number; P-value compares the kyphoplasty group to the vertebroplasty group;

Table 3. Analysis Results

\begin{tabular}{|c|c|c|c|c|}
\hline & $\begin{array}{c}\text { \# of } \\
\text { Studies }\end{array}$ & $\begin{array}{l}\text { Weighted Mean } \\
\text { Difference }\end{array}$ & $\begin{array}{l}\text { 95\% Confidence } \\
\text { Interval }\end{array}$ & P-value \\
\hline \multicolumn{5}{|l|}{ Kyphoplasty } \\
\hline Preop VAS vs. Initial Postop VAS & 7 & 5.62 & $4.84,6.40$ & $<0.00001$ \\
\hline Preop VAS vs. Final Postop VAS & 6 & 6.57 & $5.83,7.31$ & $<0.00001$ \\
\hline Initial Postop VAS vs. Final Postop VAS & 6 & 0.55 & $-0.69,1.78$ & 0.38 \\
\hline \multicolumn{5}{|l|}{ Vertebroplasty } \\
\hline Preop VAS vs. Initial Postop VAS & 14 & 5.44 & $4.87,6.02$ & $<0.00001$ \\
\hline Preop VAS vs. Final Postop VAS & 5 & 5.67 & $4.68,6.66$ & $<0.00001$ \\
\hline Initial Postop VAS vs. Final Postop VAS & 5 & 0.60 & $-0.42,1.61$ & 0.25 \\
\hline
\end{tabular}

$\#=$ number $;$ preop $=$ preoperative $;$ postop = postoperative VAS = visual analog scale 


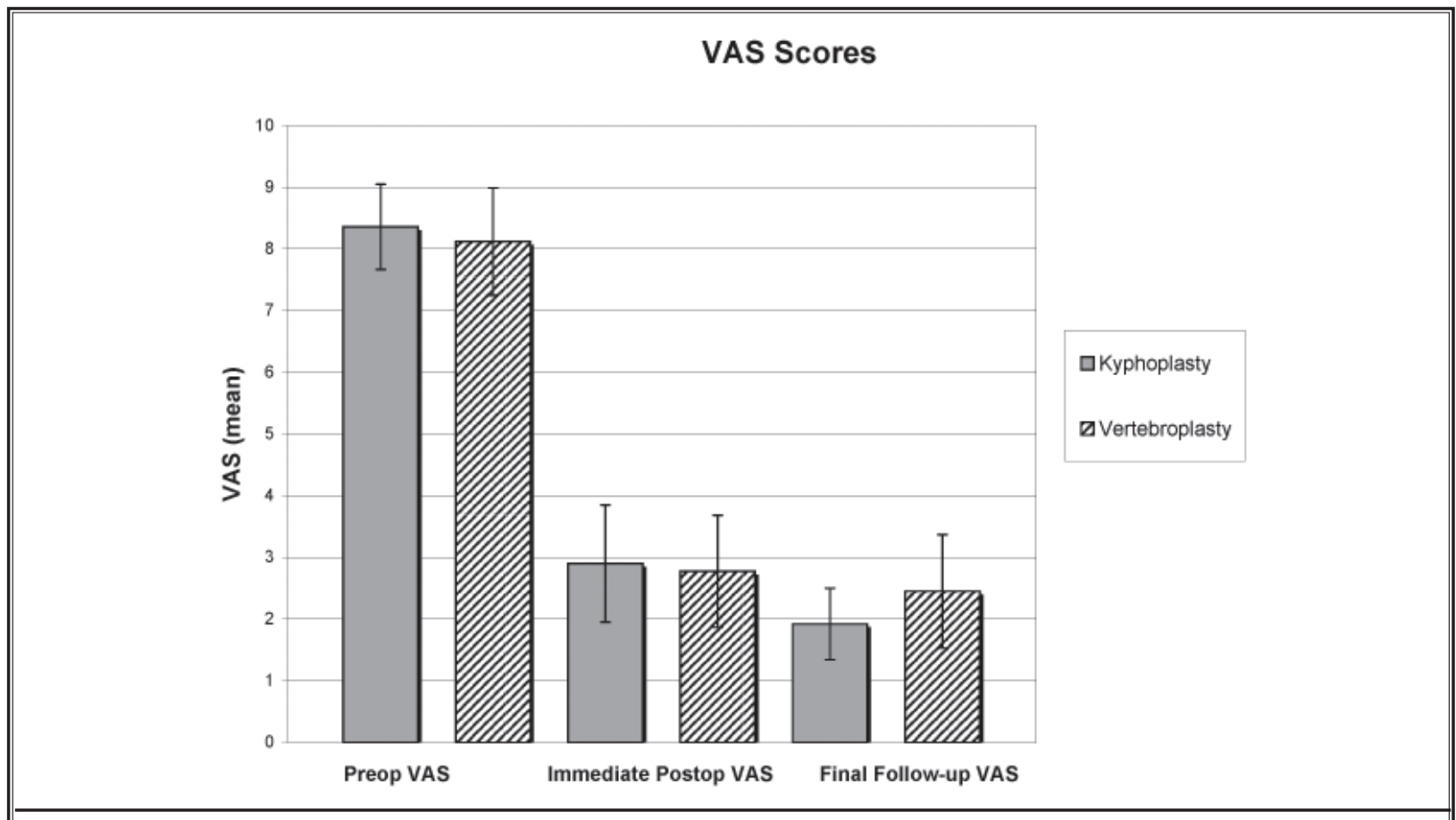

Fig.1. Graphical representation of average VAS and standard deviations.

\section{Kyphoplasty WMD}

The findings showed that patients' perception of pain was significantly improved in 2 comparisons: preoperative VAS to initial postoperative VAS and preoperative VAS to final follow-up VAS. The mean improvement on the VAS scale was $5.44(p<.00001), 6.90$ $(p<.00001)$, and $0.55(p=.38)$, respectively.

\section{Vertebroplasty WMD}

The findings showed that patients' change in perception of pain was significantly improved in 2 comparisons, preoperative VAS to initial postoperative VAS and preoperative VAS to final follow-up VAS. No significant improvement in pain reduction was found on a long-term basis. The mean improvement on the VAS scale was $5.44(p<.00001), 5.67(p<.00001)$, and $0.60(p=0.25)$, respectively.

\section{Discussion}

Several options exist for the treatment of compression fractures of the spine. Each treatment option however has its own utility. Conservative therapy, analgesic medication and bracing, was widely used for the treatment of symptomatic vertebral compression fractures. Formal open procedures, on the other hand, allow for decompression of neural structures in frac- tures with a progressive neurologic deficit and allow for stabilization if instability exists. Kyphoplasty and verterbroplasty are 2 treatments that are generally reserved for compression fractures of the spine that are associated with intractable pain without a progressive neurological deficit. In comparison to vertebroplasty, kyphoplasty has a potential advantage in that it may partially reestablish vertebral height thereby restoring stability to the spine $(11,30)$. The benefit of this however remains unknown. No study has correlated the amount of height correction to improved spinal stability.

Reliable, immediate postoperative pain relief in osteoporotic compression fractures has been shown in the literature using either kyphoplasty or vertebroplasty. Greater than $90 \%$ of patients had an immediate decrease in symptoms after either procedure (31-33). With reduced pain, patients experience an immediate improvement in the quality of life (23). Moreover, mobility of the elderly patients is necessary to reduce the possibility of blood clots, pulmonary compromise, and decubitus ulcers. Ledlie and Renfro (19) reported that out of 12 wheelchair-bound patients secondary to pain as a result of a spinal compression fracture, 10 became ambulatory at one week after kyphoplasty. Furthermore, 9 out of the 10 patients who underwent 
kyphoplasty remained ambulatory at one year after surgery).

The WMD analysis specifically evaluated each VAS comparison within one of the two groups (kyphoplasty or vertebroplasty) so the results could be compared across each group. In our analysis, we found that both kyphoplasty and vertebroplasty reduced pain by more than 5 points as measured in the VAS in the immediate postoperative and at the final follow-up period according to WMD. This reduction of pain was significant for each procedure. The final comparison of initial postoperative to final followup VAS reveals that no statistical significant change in pain reduction occurs in kyphoplasty $(p=0.38)$ and vertebroplasty $(p=0.25)$. Our review agrees with the study by Grohs et al (33) that also demonstrated a $50 \%$ reduction in pain for both procedures in the immediate postoperative period. Intuitively, we feel the common denominator for early pain relief after both kyphoplasty and vertebroplasty is the internal cement splint.

A limitation of this analysis is the lack of prospective, blinded randomized controlled trials comparing vertebroplasty and kyphoplasty in the English published literature. Therefore, the included studies are of lesser quality but still yield valid results. The strength of this analysis would be enhanced if there were available prospective blinded randomized controlled trials comparing vertebroplasty to kyphoplasty to conservative modalities. This is the next step to further investigate these procedures.

Other limitations of this study potentially leading to bias consist of comparing studies that measured outcomes based on the VAS as a numerical rating scale. Due to the multitude of scoring systems, those studies not reporting outcomes on the basis of the VAS were excluded from the study thereby possibly compromising the results. Additionally, some studies were excluded from the analysis because of the lack of sufficient data although multiple attempts were made to contact the authors of those studies. Moreover, functional outcomes were not compared due to the lack of a standard reporting scale represented in the literature. Finally, the final follow-up period was not consistent between the studies, but was a minimum of 6 months. In the available studies, final follow up ranged from 6 months to 2 years perhaps biasing the VAS rating scale for the follow-up periods. The inclusion of English only literature limits the inclusion of data from other countries where these procedures are preformed creating a selection bias. Their results could be similar or differ compared to the English literature. However, we did not have access to translators to evaluate and translate articles from various countries where English is not the primary language.

A visual analog scale and numerical rating scale provide similar information about pain. However, one scale cannot be directly converted into another since the VAS is a continuous scale and the numerical rating scale is an ordinal scale. For example, a change from 51 to $48 \mathrm{~mm}$ on the VAS is a percentage change of approximately $6 \%$. On an 11-point scale this could be represented as a change from 5 to 4; representing a change of $20 \%$, suggesting a much greater response to treatment.

In conclusion, our analysis demonstrates that both procedures reduce pain in the immediate postoperative period by approximately $50 \%$. Either procedure is appropriate for treating osteoporotic vertebral compression fractures. Randomized, controlled clinical trials with several years follow-up comparing conservative treatment, vertebroplasty, and kyphoplasty are needed to provide definitive data on how to treat osteoporotic vertebral compression fractures the most effectively. Although this study cannot provide definitive recommendations on how to treat vertebral compression fractures, it will aid clinicians in their discussions with patients who have this injury on what the current data shows. 


\section{References}

1. Prevention and management of osteoporosis. World Health Organ Tech Rep Ser 2003; 921:1-164, back cover.

2. Ray NF, Chan JK, Thamer M, Melton LJ, 3rd. Medical expenditures for the treatment of osteoporotic fractures in the United States in 1995: report from the National Osteoporosis Foundation. J Bone Miner Res 1997; 12:24-35.

3. Kinsella K, Velkoff V. U.S. Census Bureau, Series P95/01-1. An Aging World: 2001; U.S. Government Printing Office, Washington, DC.

4. Riggs BL, Melton ILJ. The worldwide problem of osteoporosis: Insights afforded by epidemiology. Bone 1995; 17:S505-S511.

5. Galibert P, Deramond H, Rosat P, Le Gars D. [Preliminary note on the treatment of vertebral angioma by percutaneous acrylic vertebroplasty]. Neurochirurgie 1987; 33:166-168.

6. Rao RD, Singrakhia MD. Painful osteoporotic vertebral fracture. Pathogenesis, evaluation, and roles of vertebroplasty and kyphoplasty in its management. J Bone Joint Surg Am 2003; 85A:2010-2022.

7. Lieberman IH, Dudeney S, Reinhardt MK, Bell G. Initial outcome and efficacy of "kyphoplasty" in the treatment of painful osteoporotic vertebral compression fractures. Spine 2001; 26:1631-1638.

8. DeLoach LJ, Higgins MS, Caplan AB, Stiff JL. The visual analog scale in the immediate postoperative period: Intrasubject variability and correlation with a numeric scale. Anesthesia and Analgesia 1998; 86: 102-106.

9. Appel NB, Gilula LA. Percutaneous vertebroplasty in patients with spinal canal compromise. Am / Roentgenol 2004; 182:947-951.

10. Berlemann U, Franz T, Orler R, Heini PF. Kyphoplasty for treatment of osteoporotic vertebral fractures: a prospective non-randomized study. Eur Spine J 2004; 13:496-501.

11. Crandall D, Slaughter D, Hankins PJ, Moore C, Jerman J. Acute versus chronic vertebral compression fractures treated with kyphoplasty: early results. Spine J 2004; 4:418-424.

12. Deen HG, Aranda-Michel J, Reimer R, Miller DA, Putzke JD. Balloon kyphoplasty for vertebral compression fractures in solid organ transplant recipi- ents: results of treatment and comparison with primary osteoporotic vertebral compression fractures. Spine $J$ 2006; 6:494-499.

13. Do HM, Kim BS, Marcellus ML, Curtis L, Marks MP. Prospective analysis of clinical outcomes after percutaneous vertebroplasty for painful osteoporotic vertebral body fractures. $\mathrm{Am} / \mathrm{Neu}$ roradiol 2005; 26:1623-1628.

14. Evans AJ, Jensen ME, Kip KE, DeNardo AJ, Lawler GJ, Negin GA, Remley KB, Boutin SM, Dunnagan SA. Vertebral compression fractures: pain reduction and improvement in functional mobility after percutaneous polymethylmethacrylate vertebroplasty retrospective report of 245 cases. Radiology 2003; 226:366-72.

15. Heini PF, Walchli B, Berlemann U. Percutaneous transpedicular vertebroplasty with PMMA: operative technique and early results. A prospective study for the treatment of osteoporotic compression fractures. Eur Spine J 2000; 9:445-450.

16. Kallmes DF, Schweickert PA, Marx WF, Jensen ME. Vertebroplasty in the midand upper thoracic spine. Am J Neuroradiol 2002; 23:1117-1120.

17. Kobayashi K, Shimoyama K, Nakamura K, Murata K. Percutaneous vertebroplasty immediately relieves pain of osteoporotic vertebral compression fractures and prevents prolonged immobilization of patients. European Radiology 2005; 15:360-367.

18. Komemushi A, Tanigawa N, Kariya S, Kojima H, Shomura Y, Sawada S. Percutaneous vertebroplasty for compression fracture: analysis of vertebral body volume by CT volumetry. Acta Radiol 2005; 46:276-279.

19. Ledlie JT, Renfro M. Kyphoplasty treatment of vertebral fractures: 2-year outcomes show sustained benefits. Spine 2006; 31:57-64.

20. Liliang PC, Su TM, Liang CL, Chen HJ, Tsai YD, Lu K. Percutaneous vertebroplasty improves pain and physical functioning in elderly osteoporotic vertebral compression fracture patients. Gerontology 2005; 51:34-39.

21. Machinis TG, Fountas KN, Feltes $\mathrm{CH}$, Johnston KW, Robinson IS. Pain outcome and vertebral body height restoration in patients undergoing kyphoplasty. Southern Med J 2006; 99:457460.
22. McGraw JK, Lippert JA, Minkus KD, Rami PM, Davis TM, Budzik RF. Prospective evaluation of pain relief in 100 patients undergoing percutaneous vertebroplasty: Results and follow-up. I Vasc Interv Radiol 2002; 13:883-886

23. McKiernan F, Faciszewski $T$, Jensen R. Quality of life following vertebroplasty. I Bone Joint Surg Am 2004; 86:2600-2606.

24. Perez-Higueras A, Alvarez L, Rossi RE, Quinones D, Al-Assir I. Percutaneous vertebroplasty: long-term clinical and radiological outcome. Neuroradiology 2002; 44:950-954.

25. Prather $\mathrm{H}$, Van Dillen L, Metzler JP, Riew KD, Gilula LA. Prospective measurement of function and pain in patients with non-neoplastic compression fractures treated with vertebroplasty. I Bone Joint Surg Am 2006; 88:334-341.

26. Tanigawa N, Komemushi A, Kariya S, Kojima H, Shomura Y, Sawada S. Radiological Follow-up of New Compression Fractures Following Percutaneous Vertebroplasty. Cardiovasc Intervent Radiol 2006; 29:92-96.

27. Voggenreiter G. Balloon kyphoplasty is effective in deformity correction of osteoporotic vertebral compression fractures. Spine 2005; 30:2806-2812.

28. Voormolen MH, Mali WP, Lohle PN, Fransen $\mathrm{H}$, Lampmann LE, van der Graaf Y, Juttmann JR, Jansssens X, Verhaar HJ. Percutaneous vertebroplasty compared with optimal pain medication treatment: shortterm clinical outcome of patients with subacute or chronic painful osteoporotic vertebral compression fractures. The VERTOS study. Am / Neuroradiol 2007; 28:555-560.

29. Zhang Q, Zou DW, Hai Y, Ma HS, Bai KW. Balloon kyphoplasty: an experience of 38 patients with painful osteoporotic vertebral compressive fractures. Chin J Traumatol 2006; 9:206-210.

30. Barr JD, Barr MS, Lemley TJ, McCann RM. Percutaneous vertebroplasty for pain relief and spinal stabilization. Spine 2000; 25:923-928.

31. Garfin SR, Yuan HA, Reiley MA. New technologies in spine: kyphoplasty and vertebroplasty for the treatment of painful osteoporotic compression fractures. Spine 2001; 26:1511-1515. 
Pain Physician: July 2007:10:583-590

32. Jensen ME, Evans AJ, Mathis JM, Kallmes DF, Cloft HJ, Dion JE. Percutaneous polymethylmethacrylate vertebroplasty in the treatment of osteoporotic vertebral body compression frac- tures: technical aspects. Am J Neuroradiol 1997; 18:1897-1904.

33. Grohs JG, Matzner M, Trieb K, Krepler P. Minimal invasive stabilization of osteo- porotic vertebral fractures: a prospective nonrandomized comparison of vertebroplasty and balloon kyphoplasty. Spinal Disord Tech 2005; 18:238-242. 